$\underline{\text { Original Articles }}$

\title{
Analysis of nutritional status and factors associated with undernutrition in children aged 6-59 months in a rural area of Sri Lanka
}

\author{
Gihan Sanjeewa Samarasekara ${ }^{1}$, ${ }^{*}$ achith Mettananda $^{2}$, Pushpa Punchihewa ${ }^{3}$
}

Sri Lanka Journal of Child Health, 2019; 48(2): 105-110

\begin{abstract}
Objective: To describe the prevalence and factors associated with undernutrition in children aged 6-59 months in a rural area of Sri Lanka.
\end{abstract}

Method: A community-based, cross-sectional study was carried out among children aged 6-59 months attending well baby clinics in Dehiattakandiya Medical Officer of Health area from November 2016 to January 2017. Data collection was done using an interviewer-administered questionnaire. Weight and height measurements were taken with calibrated instruments. Data analysis was done using logistic regression by SPSS 16.0.

Results: Four hundred and sixty four children were recruited having a mean age of $29.3 \pm 14.6$ months; $53 \%$ were females. Prevalence of stunting, underweight and wasting was $36.4 \%, 42.9 \%$ and $19.0 \%$ respectively. The following independent associations were identified: for stunting- low birth weight, breastfeeding beyond 2 years, lower maternal education and paternal smoking; for underweight- birth order more than 2, low birth weight, breastfeeding beyond 2 years, lower maternal education and paternal smoking and alcohol use; for wasting- male sex, low birth weight and paternal smoking.

${ }^{1}$ Consultant Paediatrician, District General
Hospital, Moneragala, Sri Lanka, ${ }^{2}$ Senior Lecturer,
Department of Paediatrics, Faculty of Medicine,
University of Kelaniya, Sri Lanka and Consultant
Paediatrician, Colombo North Teaching Hospital,
Ragama, Sri Lanka, ${ }^{3}$ Consultant Paediatrician,
LadyRidgeway Children's Hospital, Colombo, Sri
Lanka
${ }^{* C o r r e s p o n d e n c e: ~ s a c h i t h m e t t a @ y a h o o . c o m, ~}$
sachith.mettananda@kln.ac.lk

https://orcid.org/0000-0002-0760-0418

(Received on 06 June 2018: Accepted after revision on 20 July 2018)

The authors declare that there are no conflicts of interest Personal funding was used for the project.

Open Access Article published under the Creative Commons Attribution CC-BY License
Conclusions: Low birth weight, prolonged breastfeeding, lower maternal education level and paternal smoking had a significant association with stunting and underweight whilst male sex, low birth weight, and paternal smoking had a significant association with wasting in children aged 6-59 months.

DOI: http://dx.doi.org/10.4038/sljch.v48i2.8701

(Key words: Nutritional status, wasting, stunting, undernutrition)

\section{Background}

Undernutrition is a global health problem which is particularly common in children in the developing world. Global estimates of undernutrition among children under five years report that $22.9 \%$ of children are stunted and $7.7 \%$ are wasted ${ }^{1}$. Childhood undernutrition is extremely high in south Asia. The reported prevalences are $45 \%$ in India, $38 \%$ in Pakistan and 30\% in Sri Lanka ${ }^{2}$.

Sri Lanka, a low-middle income South Asian country, has a population over 20 million. It has extremely good health indicators for a third world country, and has the lowest maternal and child mortality figures in the region ${ }^{3}$. However, undernutrition is yet a major health problem and contributes to a significant proportion of childhood mortality and morbidity. Undernutrition prevalence is particularly high in rural poor communities as opposed to rich urban populations.

Several factors are known to be associated with undernutrition in children. Knowledge of these factors is particularly important in planning out preventive strategies to decrease the burden of undernutrition. Several previous studies have shown that a number of perinatal factors, including birth weight, birth interval, parity, gestational age $e^{4-6}$, and the child's gender ${ }^{7}$, are related to the nutritional status in children. Furthermore, socio-economic conditions ${ }^{4,8}$, living standards, water and sanitation, food intake, weaning practices, and maternal education ${ }^{4,9}$, are also shown to affect the nutritional status in young children. However, only a few studies have evaluated the burden of undernutrition and explored the factors which are associated with childhood undernutrition in rural areas of Sri Lanka. 


\section{Objectives}

To describe prevalence and factors associated with undernutrition in children aged 6-59 months in a rural area of Sri Lanka.

\section{Method}

We conducted a community based cross-sectional study in well-baby clinics in Dehiattakandiya Medical Officer of Health $(\mathrm{MOH})$ area from $1^{\text {st }}$ November 2016 to $31^{\text {st }}$ January 2017. Dehiattakandiya is an under-privileged, lowincome, remote rural area in the Eastern province of Sri Lanka. All children permanently residing in the area attend one of the two weekly well-baby clinics at least three-monthly for weight checks and routine immunization. We recruited consecutive children aged between 6 to 59 months attending well baby clinics during the study period after obtaining informed written consent from the mother. Children with acute or long-term medical problems were excluded.

Data collection was done utilizing an intervieweradministered questionnaire containing questions assessing socio-demographic background, birth and medical history, feeding practices and diet of each participant and was pre-tested in a pilot study done in a well-baby clinic of an adjacent $\mathrm{MOH}$ area. Data collectors were trained medical or nursing staff. Weight was measured using a calibrated beam balance on minimal clothing and length (under 2 years) or height (over 2 years) were measured using infantometer and stadiometer respectively by trained public health staff. Weight and length/height were plotted in WHO growth charts. Data were analysed utilizing SPSS version 16.0 with descriptive statistics and binary logistic regression. A $p$ value less than 0.05 was taken to be of statistical significance. The study was ethically approved was by the Ethics Review Committee of the Sri Lanka College of Paediatricians. Informed written consent was obtained from the child's parents before recruitment into the study.

\section{Results}

\section{Socio-demographic characteristics}

Four hundred and sixty four children were recruited into the study with a mean age of $29.3 \pm 14.6$ months. All mothers were Sinhalese and $99.8 \%$ were Buddhists. The socio-demographic characteristics of the 464 children are demonstrated in Table 1.

\section{Living conditions and personal hygiene}

The main water source in a majority $(88.8 \%)$ of families was tap water. Three hundred and ninety $(84.1 \%)$ families used safe drinking water, 222 (47.8\%) used boiled water, 94 (20.3\%) used filtered water and $107(23.1 \%)$ used chlorinated water. Sanitary latrines were available in 448 (96.6\%) households and $455(98.1 \%)$ mothers claimed that they washed hands with soap and water after going to toilet. Four hundred and twenty nine $(92.5 \%)$ mothers washed hands with soap and water before feeding their children. Substance abuse was common among fathers, $255 \quad(55.0 \%)$ being involved in some form of substance abuse; 205 (44.2\%) were smoking, 145 (31.4\%) were using alcohol and 9 (1.9\%) were using illicit drugs.

Table 1

Socio-demographic characteristics of study population $(n=464)$

\begin{tabular}{|l|c|}
\hline \multicolumn{1}{|c|}{ Characteristic } & Frequency (\%) \\
\hline Age (months) & \\
6-11 & $47(10.1)$ \\
12-23 & $140(30.2)$ \\
24-35 & $118(25.4)$ \\
36-47 & $93(20.0)$ \\
48-59 & $66(14.2)$ \\
\hline Sex & \\
Male & $216(46.6)$ \\
Female & $248(53.4)$ \\
\hline Marital status of parents & \\
Married & $460(99.2)$ \\
Unmarried & $03(0.60)$ \\
Divorced & $01(0.20)$ \\
\hline *No. of children in family & \\
One & $173(37.3)$ \\
Two & $196(42.2)$ \\
Three & $84(18.1)$ \\
Four & $09(01.9)$ \\
\hline Mother's age (years) & \\
<18 & $03(0.60)$ \\
18-25 & $113(24.4)$ \\
26-30 & $167(36.0)$ \\
31-35 & $114(24.6)$ \\
>35 & $67(14.4)$ \\
\hline Mother's education level & \\
No formal education & $02(0.40)$ \\
Up to grade 10 & $183(39.4)$ \\
Up to advanced level & $264(56.9)$ \\
Vocational training & $03(0.60)$ \\
Higher education- Diploma & $04(0.90)$ \\
Higher education- Degree & $08(01.7)$ \\
\hline Father's education level & \\
No formal education & $06(01.3)$ \\
Up to grade 10 & $221(47.6)$ \\
Up to advanced level & $225(48.5)$ \\
Vocational training & $04(0.90)$ \\
Higher education - Diploma & $03(0.60)$ \\
Higher education - Degree & $05(01.1)$ \\
\hline **Father's occupation & \\
Unemployed & $03(0.6)$ \\
Employment with monthly salary & $168(36.2)$ \\
Daily paid employment & $86(18.5)$ \\
Farmer & $150(32.3)$ \\
Fisherman & $01(0.20)$ \\
Trader & $23(05.0)$ \\
Manufacturing/ handicraft & $04(0.90)$ \\
Live stock & $06(01.3)$ \\
Other & $20(04.3)$ \\
\hline *Monthly family income (LKR) & \\
<10,000 & \\
10,001-20,000 & \\
20,001-40,000 & \\
$>40,000$ & \\
*Data missing from 2 participants; ** Data missing from 3 \\
participants & \\
LKR: Sri Lankan rupees & \\
& \\
\hline
\end{tabular}

\section{Feeding practices}

Mean duration of exclusive breastfeeding in the study population was $5.92 \pm 0.59$ months. Age of initiation of complementary feeding ranged from 212 months. A majority $(80.0 \%)$ of babies were 
started on complementary feeds at 6 months and in $62(13.4 \%)$ children the commencement of complementary feeding was delayed beyond 6 months. Most children (72.6\%) were given more than 3 meals containing solids per day; the number of meals with solid foods per day were; one $-6.5 \%$, two $-19.0 \%$, three $-49.4 \%$, four $-17.5 \%$, five $-5.0 \%$ and six $-0.9 \%$. Most kids $(85.6 \%)$ were receiving nutritional supplements or nutritional therapy; 355 (76.5\%) received nutritional supplements (Thriposha) and 27 (5.8\%) received high energy biscuits. Forty three (9.3\%) and $49(10.6 \%)$ children respectively received iron and multivitamin supplements.

\section{Nutritional status and prevalence of undernutrition}

Anthropometric data showed that prevalence of stunting, underweight and wasting was $36.4 \%$, $42.9 \%$ and $19.0 \%$ respectively. Anthropometric data and prevalence of nutritional problems in each age group are shown in Tables 2 and 3 respectively.

Table 2: Anthropometric characteristics of the study population $(\mathrm{n}=464)$

\begin{tabular}{|l|c|c|c|}
\hline Z Score (SD value) & Length or height / age & Weight / age & Weight / length or height \\
\hline$>+2 S D$ & - & $1(0.2 \%)$ & $10(2.2 \%)$ \\
\hline+1 SD to +2SD & - & $4(0.9 \%)$ & $10(2.2 \%)$ \\
\hline Median to +1SD & $7(1.5 \%)$ & $5(1.1 \%)$ & $37(8.0 \%)$ \\
\hline Median to -1SD & $89(19.2 \%)$ & $74(15.9 \%)$ & $171(36.9 \%)$ \\
\hline -1SD to -2SD & $199(42.9 \%)$ & $181(39.0 \%)$ & $148(31.9 \%)$ \\
\hline -2SD to -3SD & $129(27.8 \%)$ & $150(32.3 \%)$ & $62(13.4 \%)$ \\
\hline$<-3 S D$ & $40(8.6 \%)$ & $49(10.6 \%)$ & $26(5.6 \%)$ \\
\hline
\end{tabular}

Table 3: Prevalence of stunting, underweight and wasting in different age groups

\begin{tabular}{|l|c|c|c|}
\hline \multirow{2}{*}{ Age group } & \multicolumn{2}{|c|}{ Number of individual with nutritional problems (\%) } \\
\cline { 2 - 4 } & Stunting & Underweight & Wasting \\
\hline $6-11$ months $(\mathrm{n}=47)$ & $08(17.0 \%)$ & $15(31.9 \%)$ & $12(25.5 \%)$ \\
\hline $12-23$ months $(\mathrm{n}=140)$ & $45(32.1 \%)$ & $47(33.6 \%)$ & $28(20.0 \%)$ \\
\hline $24-35$ months $(\mathrm{n}=118)$ & $56(47.5 \%)$ & $68(57.6 \%)$ & $23(19.5 \%)$ \\
\hline $36-47$ months $(\mathrm{n}=93)$ & $37(39.8 \%)$ & $45(48.4 \%)$ & $16(17.2 \%)$ \\
\hline $48-59$ months $(\mathrm{n}=66)$ & $23(34.8 \%)$ & $24(36.4 \%)$ & $09(13.6 \%)$ \\
\hline Total (n=464) & $\mathbf{1 6 9 ( 3 6 . 4 \% )}$ & $\mathbf{1 9 9}(\mathbf{4 2 . 9 \% )}$ & $\mathbf{8 8 ( 1 9 . 0 \% )}$ \\
\hline
\end{tabular}

\section{Factors associated with undernutrition}

Next, we performed binary logistic regression analysis with the aim of identifying independent factors which are associated with undernutrition. Several socio-demographic and health related factors including sex, birth order, mode of delivery, maturity, birth weight, breastfeeding duration, mother's education level, monthly family income, paternal smoking and alcohol abuse were included in the logistic regression model. This analysis identified that low birth weight $(\mathrm{p}<0.05)$, prolonged breastfeeding beyond 2 years $(\mathrm{p}<0.05)$, lower maternal education level $(\mathrm{p}<0.001)$ and paternal smoking $(\mathrm{p}<0.01)$ are significantly associated with a higher risk of stunting (Table 4).

Table 4: Association between socio-demographic and health related factors and stunting*

\begin{tabular}{|c|c|c|c|c|c|}
\hline Socio-demographic/ health factor & $\begin{array}{c}\text { No. }(\%) \text { of } \\
\text { stunted } \\
\text { children with } \\
\text { associated } \\
\text { factor }(n=159)\end{array}$ & $\begin{array}{l}\text { No. }(\%) \text { control } \\
\text { (non-stunted) } \\
\text { children with } \\
\text { associated factor } \\
(n=277)\end{array}$ & $\begin{array}{c}\text { Odds ratio } \\
\text { (95\%CI) } \\
\text { [Unadjusted] }\end{array}$ & $\begin{array}{c}\text { Odds ratio } \\
\text { (95\%CI) } \\
\text { [Adjusted] }\end{array}$ & $\begin{array}{c}\mathbf{p} \\
\text { value }\end{array}$ \\
\hline Male sex & $66(41.5 \%)$ & $137(49.5 \%)$ & $0.72(0.48-1.07)$ & $0.67(0.43-1.04)$ & 0.076 \\
\hline Birth order $>2$ & $35(22.0 \%)$ & $53(19.1 \%)$ & $1.19(0.73-1.92)$ & $0.94(0.54-1.62)$ & 0.832 \\
\hline Delivered by LSCS & $37(23.3 \%)$ & $53(19.1 \%)$ & $1.28(0.79-2.06)$ & $1.37(0.80-2.33)$ & 0.243 \\
\hline Prematurity & $18(11.3 \%)$ & $20(7.2 \%)$ & $1.64(0.84-3.20)$ & $1.18(0.53-2.59)$ & 0.68 \\
\hline Low birth weight & $43(27.0 \%)$ & $42(15.2 \%)$ & $2.07(1.28-3.35)$ & $1.93(1.08-3.45)$ & $<0.05$ \\
\hline Breastfeeding beyond 2 years & $82(51.6 \%)$ & $99(35.7 \%)$ & $1.91(1.28-2.84)$ & $1.77(1.14-2.74)$ & $<0.05$ \\
\hline Maternal education level - below grade 10 & $95(59.7 \%)$ & $85(30.7 \%)$ & $3.35(2.23-5.03)$ & $2.23(1.42-3.50)$ & $<0.001$ \\
\hline Family income $<$ LKR 20,000 per month & $88(55.3 \%)$ & $118(42.6 \%)$ & $1.67(1.12-2.47)$ & $1.40(0.90-2.17)$ & 0.132 \\
\hline Paternal smoking & $102(64.2 \%)$ & $96(34.7 \%)$ & $3.37(2.24-5.07)$ & $2.29(1.43-3.68)$ & $<0.01$ \\
\hline Paternal alcohol abuse & $74(46.5 \%)$ & $66(23.8 \%)$ & $2.78(1.83-4.22)$ & $1.58(0.97-2.59)$ & 0.065 \\
\hline
\end{tabular}

${ }^{*}$ Data incomplete in 28 subjects

Factors significantly associated with a higher risk of underweight were; birth order above $2(\mathrm{p}<0.05)$, low birth weight $(\mathrm{p}<0.01)$, prolonged breastfeeding beyond 2 years $(\mathrm{p}<0.05)$, lower maternal education level $(\mathrm{p}<0.001)$ and paternal smoking $(\mathrm{p}<0.001)$ and alcohol abuse $(\mathrm{p}<0.05)$ (Table 5). 
Table 5: Association between socio-demographic and health related factors and underweight

\begin{tabular}{|l|c|c|c|c|c|}
\hline Socio-demographic/ health factor & $\begin{array}{c}\text { No. (\%) of } \\
\text { underweight } \\
\text { children with } \\
\text { associated } \\
\text { factor } \mathbf{( n = 1 8 8 )}\end{array}$ & $\begin{array}{c}\text { No. (\%) control } \\
\text { (non-underweight) } \\
\text { children with } \\
\text { associated factor } \\
\text { (n=248) }\end{array}$ & $\begin{array}{c}\text { Odds ratio } \\
\text { (95\%CI) } \\
\text { [Unadjusted] }\end{array}$ & $\begin{array}{c}\text { Odds ratio } \\
\text { (95\%CI) } \\
\text { [Adjusted] }\end{array}$ & $\begin{array}{c}\text { value } \\
\text { value }\end{array}$ \\
\hline Male sex & $94(50.0 \%)$ & $109(44.0 \%)$ & $1.27(0.87-1.86)$ & $1.31(0.84-2.04)$ & 0.221 \\
\hline Birth order $>2$ & $50(26.6 \%)$ & $38(15.3 \%)$ & $2.00(1.24-3.21)$ & $1.80(1.05-3.10)$ & $<0.05$ \\
\hline Delivered by caesarean section & $41(21.8 \%)$ & $49(19.8 \%)$ & $1.13(0.71-1.80)$ & $1.11(0.65-1.89)$ & 0.695 \\
\hline Prematurity & $20(10.6 \%)$ & $18(7.3 \%)$ & $1.52(0.78-2.96)$ & $0.95(0.42-2.12)$ & 0.902 \\
\hline Low birth weight & $50(26.6 \%)$ & $35(14.1 \%)$ & $2.20(1.36-3.57)$ & $2.21(1.22-4.01)$ & $<0.01$ \\
\hline Breastfeeding beyond 2 years & $93(49.5 \%)$ & $88(35.5 \%)$ & $1.78(1.20-2.62)$ & $1.76(1.13-2.75)$ & $<0.05$ \\
\hline Maternal education level - below grade 10 & $112(59.6 \%)$ & $68(27.4 \%)$ & $3.90(2.60-5.83)$ & $2.60(1.65-4.09)$ & $<0.001$ \\
\hline Family Income $<20,000$ rupees per month & $95(50.5 \%)$ & $111(44.8 \%)$ & $1.26(0.86-1.84)$ & $0.87(0.56-1.36)$ & 0.553 \\
\hline Paternal smoking & $122(64.9 \%)$ & $76(30.6 \%)$ & $4.18(2.79-6.26)$ & $2.58(1.62-4.10)$ & $<0.001$ \\
\hline Paternal alcohol abuse & $89(47.3 \%)$ & $51(20.6 \%)$ & $3.47(2.28-5.28)$ & $1.89(1.15-3.11)$ & $<0.05$ \\
\hline
\end{tabular}

Wasting was significantly associated with male sex $(\mathrm{p}<0.01)$, low birth weight $(\mathrm{p}<0.01)$ and paternal smoking $(\mathrm{p}<0.05)$ (Table 6). Acute illnesses during past two weeks, maternal employment status and paternal education level were not significantly associated with undernutrition in children.

Table 6: Association between socio-demographic and health related factors and wasting*

\begin{tabular}{|c|c|c|c|c|c|}
\hline Socio-demographic/ health factor & $\begin{array}{c}\text { Number }(\%) \text { of } \\
\text { wasted } \\
\text { children with } \\
\text { associated } \\
\text { factor }(n=84)\end{array}$ & $\begin{array}{c}\text { Number }(\%) \\
\text { control (non- } \\
\text { wasted) children } \\
\text { with associated } \\
\text { factor }(n=352)\end{array}$ & $\begin{array}{c}\text { Odds ratio } \\
\text { (95\%CI) } \\
\text { [Unadjusted] }\end{array}$ & $\begin{array}{c}\text { Odds ratio } \\
\text { (95\%CI) } \\
\text { [Adjusted] }\end{array}$ & $p$ value \\
\hline Male sex & $53(63.1 \%)$ & $150(42.6 \%)$ & $2.30(1.40-3.76)$ & $2.19(1.31-3.65)$ & $<0.01$ \\
\hline Birth order $>2$ & $20(23.8 \%)$ & $68(19.3 \%)$ & $1.30(0.74-2.30)$ & $1.41(0.76-2.60)$ & 0.271 \\
\hline Delivered by caesarean section & $16(19.0 \%)$ & $74(21.0 \%)$ & $0.88(0.48-1.61)$ & $0.84(0.44-1.58)$ & 0.597 \\
\hline Prematurity & $9(10.7 \%)$ & $29(8.2 \%)$ & $1.33(0.60-2.94)$ & $0.85(0.35-2.08)$ & 0.735 \\
\hline Low Birth weight & $28(33.3 \%)$ & $57(16.2 \%)$ & $2.58(1.51-4.41)$ & $2.47(1.35-4.52)$ & $<0.01$ \\
\hline Breastfeeding beyond 2 years & $33(39.3 \%)$ & $148(42.0 \%)$ & $0.89(0.54-1.45)$ & $0.91(0.54-1.53)$ & 0.727 \\
\hline Maternal education level - below grade 10 & $44(52.4 \%)$ & $136(38.6 \%)$ & $1.74(1.08-2.82)$ & $1.33(0.77-2.29)$ & 0.298 \\
\hline Family Income $<20,000$ rupees per month & $39(46.4 \%)$ & $167(47.4 \%)$ & $0.96(0.59-1.54)$ & $0.80(0.48-1.34)$ & 0.409 \\
\hline Paternal smoking & $52(61.9 \%)$ & $146(41.5 \%)$ & $2.29(1.40-3.73)$ & $1.80(1.02-3.19)$ & $<0.05$ \\
\hline Paternal alcohol abuse & $36(42.9 \%)$ & $104(29.5 \%)$ & $1.78(1.09-2.91)$ & $1.28(0.72-2.28)$ & 0.385 \\
\hline
\end{tabular}

\section{Discussion}

This study was conducted in a prototype economically deprived rural area of Sri Lanka which is located in the Eastern Province, over $200 \mathrm{~km}$ away from the capital, Colombo. Prevalence rates of stunting, underweight and wasting reported were $36 \%, 42 \%$ and $19 \%$ respectively. These figures are higher than the Sri Lankan prevalence rates of stunting, underweight and wasting which are reported as $18 \%, 21 \%$ and $15 \%$ respectively ${ }^{3}$. Similarly, prevalence rates are higher than the global prevalence rates which are reported as $22 \%, 16 \%$ and $7 \%$ for stunting, underweight and wasting respectively ${ }^{1,10}$. These findings reflect the poor nutritional status in rural communities of Sri Lanka where a majority of families live in poverty. In this study, highest prevalence of stunting and underweight were reported in the 24-35 month age group whereas the highest prevalence of wasting was observed in the 6-11 month age group. These findings are in accordance with the previous results of the Demographic Health Survey of Sri Lanka conducted in $2006^{3}$.
This study revealed several factors which are positively associated with undernutrition. Of note, stunting, underweight and wasting were significantly greater in children who were born with low birth weight. Similar findings were reported in several studies including one done in the southern part of Sri Lanka ${ }^{11}$. Additionally, we found that higher birth order (over 2) was significantly associated with underweight in children. Comparable results were reported in a study done in Ethiopia which revealed that children of mothers who delivered three or more offspring were more likely to become underweight in comparison with children of mothers who delivered less than three offspring ${ }^{12}$. This can be partially due to the fact that children have a higher chance of being neglected in larger families compared to smaller ones. We also found that breastfeeding beyond 2 years of age was significantly associated with stunting and underweight. No significant relationship was found between wasting and duration of breastfeeding. These findings suggest that prolonged breastfeeding may decrease the calorie intake of children and could lead to chronic malnutrition. 
Another significant association of stunting and underweight was lower maternal education level. Several other studies done in the southern and northern parts of Sri Lanka have also concluded that all 3 undernutrition indicators were increasing with declining maternal educational level ${ }^{13,14}$. Additionally, this study revealed that all 3 undernutrition indicators were significantly increased with paternal smoking. Prevalence of paternal smoking in this area (44\%) was comparatively higher than in the rest of the Sri Lanka which reports extremely low rates of smoking in the world. Although there could be several confounding factors for higher risk of stunting, underweight and wasting in children of smoking fathers, it showed independent associations in logistic regression after adjusting for other variables.

In our study, there was no statistically significant relationship between undernutrition and acute illness during past two weeks. Same had been shown in studies done in the southern and western parts of Sri Lanka ${ }^{12,13}$. However, contrasting findings have been reported in several studies done in other countries; studies done in Ethiopia, Jordan and Brazil revealed that diarrhoeal diseases and respiratory infections were determinants of undernutrition in children ${ }^{15,16}$.

\section{Conclusions}

This study revealed that prevalence of stunting, underweight and wasting in Dehiattakandiya $\mathrm{MOH}$ area is much higher than the national and global figures. Low birth weight, prolonged breastfeeding, lower maternal education level and paternal smoking were significantly associated with both stunting and underweight whereas male sex, low birth weight and paternal smoking were significantly associated with wasting in children aged 6-59 months. Birth order above two and paternal alcohol abuse were significantly associated with underweight but not with stunting or wasting.

\section{Acknowledgements}

We are grateful to all children and their parents for participating in this study and the staff at the $\mathrm{MOH}$ office in Dehiattakandiya in Sri Lanka, for providing assistance in the collection of data.

\section{References}

1. WHO. UNICEF-WHO-The World Bank: Joint child malnutrition estimates - Levels and trends: World Health Organisation; 2017

2. Khan AA, Bano N, Salam A. Child malnutrition in South Asia: A comparative perspective. South Asian Survey 2007; 14(1):129-45. https://doi.org/10.1177/097152310701400 110

3. Department of census and statistics. Demographic and Health Survey report. Colombo: Department of Census and Statistics; 2006.

4. Jesmin A, Yamamoto SS, Malik AA, Haque MA. Prevalence and determinants of chronic malnutrition among preschool children: a cross-sectional study in Dhaka City, Bangladesh. Journal of Health, Population and Nutrition 2011; 29(5):4949.

https://doi.org/10.3329/jhpn.v29i5.8903

5. Bhuriya A, Woksynalak B, Soysa D. Socioeconomic determinants of childhood nutritional status. Food and Nutrition Bulletin 1986; 3:3-7.

6. Powell CA, Grantham-McGregor S. The ecology of nutritional status and development in young children in Kingston, Jamaica. American Journal of Clinical Nutrition 1985; 41(6):1322-31. https://doi.org/10.1093/ajcn/41.6.1322 PMid: 4003336

7. Gopaldas T, Patel P, Bakshi U. Selected economic environmental, maternal and child factors, associated with nutritional status of infants and toddlers. Food and Nutrition Bulletin 1988; 10(4):29-34.

8. Weerasinghe C. Socio economic and cultural factors contributing to malnutrition, Dissertation for MSc Nutrition; 1981.

9. UNICEF. Situational analysis of children and women in Sri Lanka. UNICEF; 1987.

10. UNICEF. UNICEF status of children nutrition in Sri Lanka. UNICEF; 2013.

11. Peiris T, Wijesinghe D. Nutritional status of fewer than 5 Year-Old Children and its relationship with maternal nutrition knowledge in Weeraketiya DS division of Sri Lanka. Tropical Agricultural Research 2010; 21(4):330-9.

https://doi.org/10.4038/tar.v21i4.3309

12. Nestle PS, Rathnayaka RMK. Nutrition and Health Status of Children, Nutrition and Poverty division. Battaramula: Ministry of policy Planning and Implementation- Sri Lanka.; 1997. 
13. Obeysekara NH, Jayathissa R, Wijesinghe CJ. Nutritional status and associated feeding practices among children aged 624 months in a selected community in Sri Lanka: A cross sectional study. European Journal of Preventive Medicine 2015; 3(21):15-23.

14. Jayatissa R, Hossain M, Nanayakkara L. Assessment of nutritional status and associated factors in Nothern province. Colombo: Medical Research Institute in collaboration with UNICEF and Ministry of health; 2012.

15. Tamiru MW, Tolessa BE, Abera SF. Under Nutrition and Associated Factors Among Under-Five Age Children of Kunama Ethnic Groups in Tahtay Adiyabo Woreda, Tigray Regional State, Ethiopia: Community Based Study. International Journal of Nutrition and Food Sciences 2015; 4(3):277-88. https://doi.org/10.11648/j.ijnfs.20150403. 15
16. Giugliani ER, Seffrin CF, Goldan M, Horn JF, Ebrahim GJ. The malnourished children of the urban squatter families: a study in Porto Alegre, Brazil. Journal of Tropical Pediatrics 1987; 33(4):194-8. https://doi.org/10.1093/tropej/33.4.194 PMid: 3669136 